\title{
School engagement as a mediator in students' social relationships and academic performance: a survey based on CiteSpace
}

\author{
Yin $\mathrm{Li}$
}

School of Information, Central University of Finance and Economics, Beijing, China, and

Leiju Qiu and Baowen Sun

China Center for Internet Economy Research, Central University of Finance and Economics, Beijing, China

\begin{abstract}
Purpose - In studies related to education, sociology and economics, the relationship between students' social relationships and their academic performance is one of the most important research topics; a large number of research studies have focused on it. This study aims to analyze the previous studies about social interaction and academic performance and attempts to reveal the underlying mechanism.

Design/methodology/approach - This study uses CiteSpace to analyze 1,843 articles on social relationships and academic performance from 2001 to 2019. According to the co-cited literature network results in CiteSpace, this study proposes an adapted conceptual framework of the relationship between social relationships and academic performance. This paper further examines more studies about the two most-cited articles in the co-cited literature network for better understanding.

Findings - From the results of the co-cited literature network, this study determines that school engagement is an important mediator between social relationships and academic performance. This paper further examines studies on school engagement and determine that, along with the self-determination theory, school engagement is influenced by multiple components of self-determination theory: autonomy, competence and relatedness.

Originality/value - According to the visual result in CiteSpace, this study examines a research trend in which researchers scholars start to conduct micro and detailed empirical research on the impact of the specific social networks on academic performance because of the progress of information technology. Therefore,
\end{abstract}

(c) Yin Li, Leiju Qiu and Baowen Sun. Published in International Journal of Crowd Science. Published by Emerald Publishing Limited. This article is published under the Creative Commons Attribution (CC BY 4.0) license. Anyone may reproduce, distribute, translate and create derivative works of this article (for both commercial and non-commercial purposes), subject to full attribution to the original publication and authors. The full terms of this license may be seen at http://creativecommons.org/ licences/by/4.0/legalcode

We thank the participants in the International Conference on Crowd Science and Engineering (ICCSE' 2019) for their useful comments. All remaining errors are ours. We are grateful for the financial support from the National Key Research and Development Program of China (2017YFB1400100), the Education and Teaching Reform Fund of Central University of Finance and Economics in 2018 (2018GRYBJG10), the National Natural Science Foundation of China (NSFC71804206) and the Beijing Social Science Foundation Research Base Project (17JDYJB018), the Young Teachers Development Fund of Central University of Finance and Economics (QJJ1826), the Program for First-class Discipline Construction in Central University of Finance and Economics and the Beijing Program for "Double First-class" Construction Project of Central Universities.

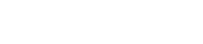



technology, such as data mining or data analysis, in this academic field will become a mainstream practice in the future.

Keywords Academic performance, Self-determination theory, Social relationships

Paper type Literature review

\section{8}

\section{Introduction}

During the interaction of individuals, the evolution of human cognitive ability is one of the most important topics in the social sciences of collective intelligence. In studies related to education, sociology and economics, academic performance is often used as a variable to measure students' individual cognitive ability. Therefore, there is a large body of literature that has examined academic performance. In this study, we focus on school, a relatively closed social organization and postulate two research questions:

$R Q 1$. Does the social interaction between different individuals in a group affect their academic performance?

RQ2. What is the mechanism?

We select social relationships, social networks, peer relationships, academic performance and academic achievement as keywords in Web of Science core collection, and import the search results (1,843 articles and 83,064 references) between 2001 and 2019 into CiteSpace. We use CiteSpace to clean up the duplication and cluster the references to form co-cited network visualizations. The results show that, compared to other articles, the two articles cited the most number of times have significantly higher citations. Both articles are about school engagement, which indicates that school engagement is an important factor in studying the relationship between social relationships and academic performance.

After analyzing the literature further, we determine that school engagement, as an intermediate variable between social relationships and academic performance, plays an intermediary role in their relationship. We then analyze the literature on school engagement, which shows that self-determination theory is a key element that can be used to explain how social relationships influence academic performance. Note that autonomy, competence and relatedness are the three components of self-determination theory that affect school engagement.

The remainder of this paper is organized as follows. First, we will introduce the analysis of literature using CiteSpace and the conceptual framework in Section 2. We then discuss the literature analysis resulting from four factors that affect social relationships in Section 3. Finally, we discuss the emergence of school engagement in Section 4 and provide a conclusion in Section 5.

\section{Literature analysis using CiteSpace}

We describe four visualizations of the peer relationship and academic performance data set produced using CiteSpace:

(1) a merged network of pathfinder-pruned co-cited networks;

(2) the merged network shows in time-line view; and

(3) the merged network shows in the time-zone view. 
Figure 1 shows the merged network of pathfinder-pruned co-cited networks. This merged network is the result of merging several time-slice networks. Co-cited networks do not explicitly feature research fronts; however, they represent the footprint of a research front. The most prominent study in the visualization is that by Furrer and Skinner (2003) in the central area. It is this study that emphasizes how children's sense of relatedness is vital to their academic engagement and performance, whereas relatedness to peers is one of the important predictors of school engagement. Next to Furrer and Skinner's (2003) study is another prominent article by Fredricks et al. (2004), which reviews definitions, measures, precursors and outcomes of school engagement. The central area formed by these two prominent articles is surrounded by five densely connected clusters.

The clusters in the northwest of the central area have several prominent articles, including those by Ryan (2001), Roorda et al. (2011), Wentzel and Caldwell (1997) and Kirschner and Karpinski (2010). The cluster near the central area is primarily a discussion about how peer groups affect student academic engagement and performance. Finally, the cluster far from the central area is primarily a discussion on how the use of social media affects student academic engagement and performance.

The cluster located to the right of the visualization has apparently been formed recently because the prevalent yellow convex hull indicates that its components are cited around 2015. The highly cited articles in this cluster include Flashman (2012) and McPherson et al. (2001). This cluster primarily focuses on social network analysis, which has become a hot topic as per the use of big data technology.

The cluster located toward the bottom of the visualization has been formed relatively long ago back because the prevalent purple convex hull in this cluster indicates that its components are cited around 2005. This cluster primarily focuses on the relationship between students' social background and their academic performance.

Figure 2 shows the merged network of pathfinder-pruned co-cited networks in a timeline view. The timeline could be divided into two segments. The first includes the nodes before 2006, with dark purple links on the upper left and bottom left of the visualization. The other one includes the nodes after 2006, with light yellow links at the middle right of the visualization. We can see that the two most cited articles of Furrer and Skinner (2003) and

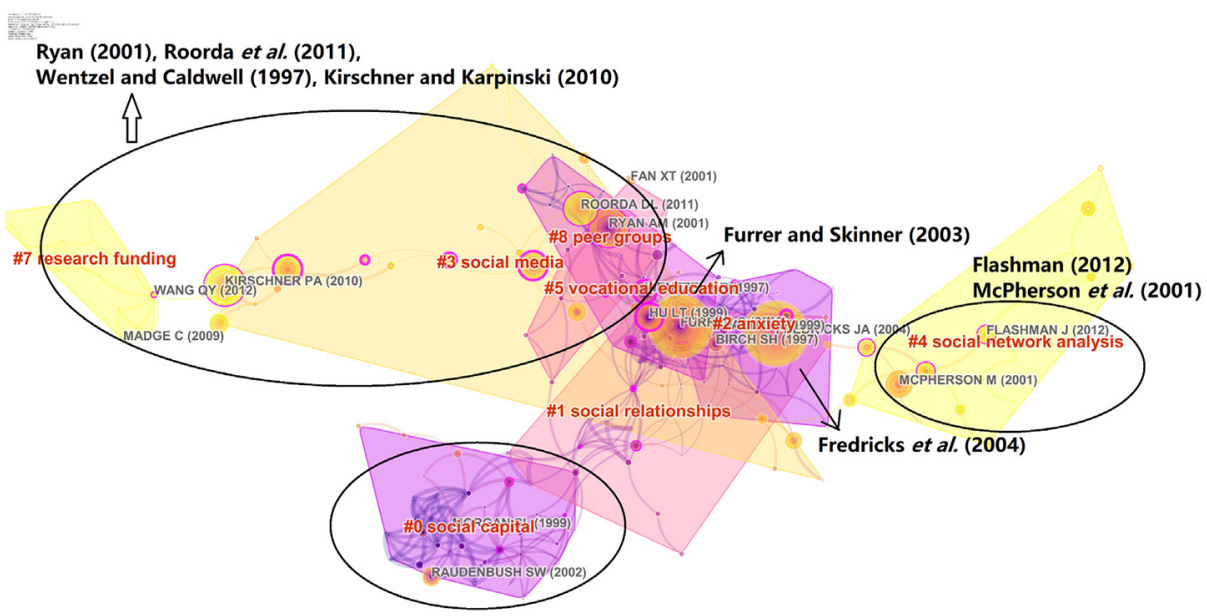

Figure 1. The merged network of pathfinder-pruned co-cited networks 
IJCS

5,1

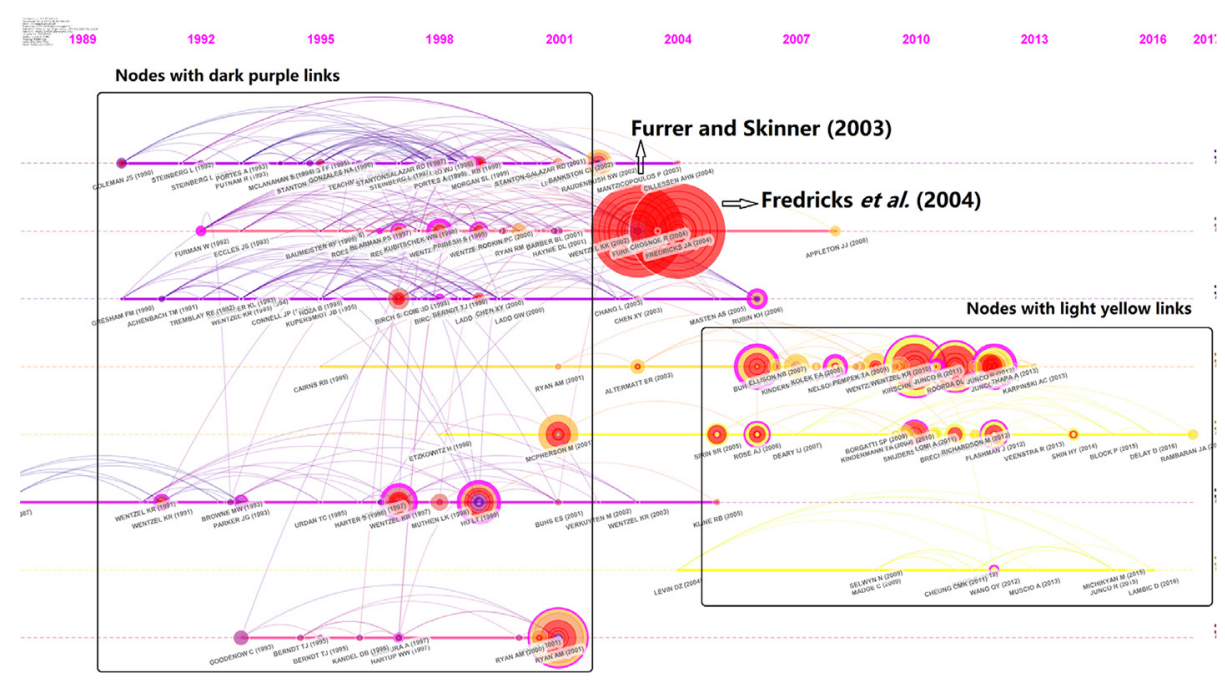

Figure 2.

The merged network shows in time-line view

Fredricks et al. (2004), i.e. the two nodes with the largest circle, are in the middle of the two segments.

To demonstrate the details of temporal relation change, Figure 3 shows the merged network in the time-zone view. We can identify the two segments of research on how social relationships affect academic performance. The bottom left nodes with dark purple links refer to how peer relationships affect student-school engagement and academic performance. The middle notes, with both dark purple and light yellow links, focus on the same research topic in more recent years, whereas the upper right nodes with light yellow links show the research front articles.

Figure 3.

The merged network shows in time-zone view

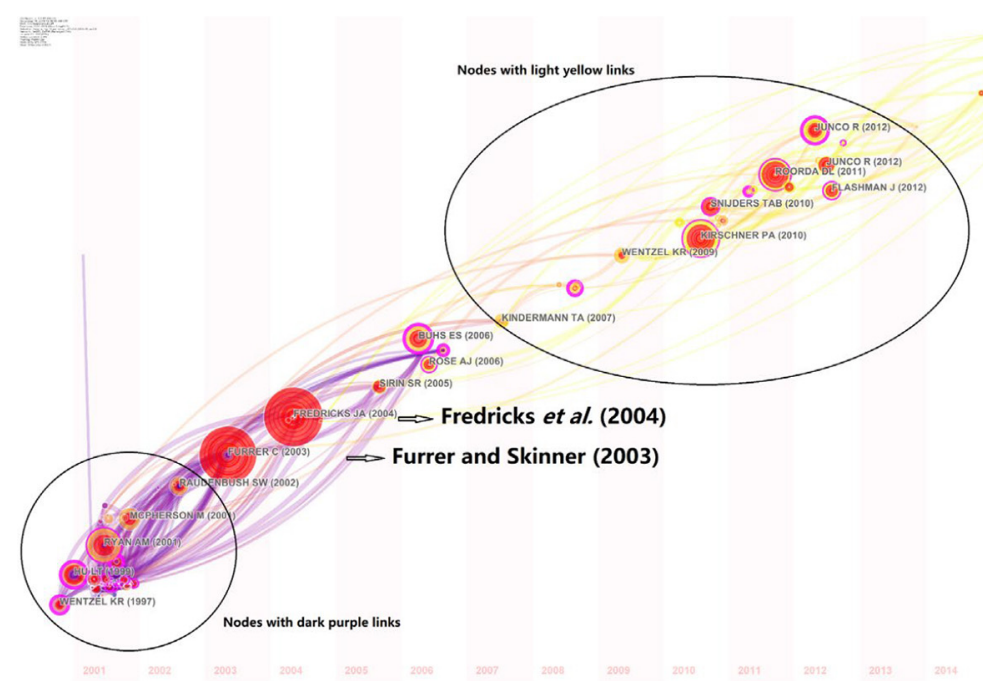


The methods in CiteSpace help us to improve the clarity and interpretability of the relation between social relationships and academic performance. Moreover, identifying pivotal points based solely on the topological properties of a network is of practical value. The visualizations in CiteSpace enable us to identify both the most prominent articles, such as Furrer and Skinner (2003) and Fredricks et al. (2004), and critical points in the course of transition from one specialty to another. In our case, we quickly identify the mainstream articles and extract key variables, such as school engagement, from the two prominent articles. Next, we improve the conceptual framework of social relationships and academic performance by adding the variable of school engagement.

\subsection{Conceptual framework of social relationships and academic performance}

Figure 4 shows the adapted conceptual framework of social relationships and academic performance. Based on CiteSpace's analysis of co-cited literature, we determine that there are two most-cited studies related to school engagement and these two studies are at the joint of the two segments in the time-line. Therefore, school engagement should be an important component in the relationship between social relationships and academic performance; consequently, we consider these two studies as the watershed and divide the other literature into two parts: the literature before the two articles and the literature after them. Furthermore, we determine the literature extant before the two articles by the type of social relationships that they discuss.

\section{Factors affecting social relationships}

Social relationships refer to the sum of the social interactions between people in the process of joint activities. There is a vast body of literature on the relationship between social relationships and academic performance. McPherson believes that geographic propinquity, engendered by families and organizations, can create contexts in which homophilous relations form. Students live and study in the environment of family and school for a long time; thus, their academic performance will be influenced by both family and school contexts (McPherson et al., 2001). In the existing literature, the different types of social relations can be divided into four influencing factors, namely, the family factor, teacher factor, peer factor and individual factor; moreover, they have various effects on academic performance.

\subsection{Family factor}

Family, as the first social environment in which children socialize, has an important influence on the formation of students' character and behavior. Resnick through interview data with teenagers in Grades 7-12 determines that family and school contexts, as well as personal characteristics, are related to adolescent health and risky behavior (Resnick et al., 1997). Whether the impact of family on students will affect students' academic performance has been examined by different researchers. Furman determines that family members, teachers and friends have both a positive and significant impact on students' academic

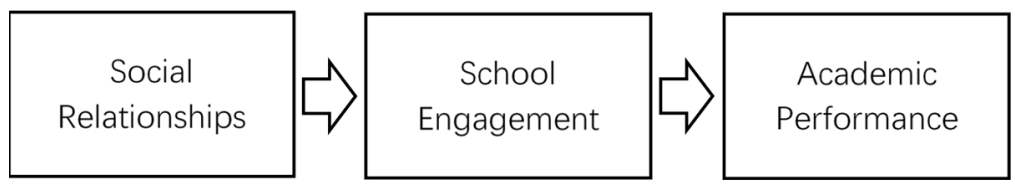

Figure 4.

Conceptual framework of social relationships and academic performance 
IJCS
5,1

performance through the statistics of students' academic performance in their four growth stages (Furman and Buhrmester, 1992). Fan determines that the relationship between parents' expectations of children's educational achievement and students' academic achievement is the strongest; however, that between parents' family supervision and students' academic achievement is the weakest (Fan and Chen, 2001). This shows that parents, as the first teachers of children, interact with their children differently, which may have different effects on their academic performance. This effect may be both directly related and indirectly affected by their academic performance. Wentzel believes that social interaction between students and their parents can teach them about themselves and what they are required to do to become acceptable and competent members of their social world. The quality of the relationship between students and their parents will have a significant impact on students' motivation and performance (Wentzel, 1999).

\subsection{Teacher factor}

The teacher, as the instructor of and participant in students' academic activities, has a direct impact on students' academic performance; some researchers have determined that the teacher's attitude and behavior toward students will indirectly affect their academic performance. Goodenow determines that the subjective sense of belonging and support is significantly associated with academic performance; moreover, students' perceptions of the support, interest and respect they received from their teachers is the single most influential component of belonging and support (Goodenow, 1993). Wentzel determines that teacher support is both a positive predictor of both types of social goal pursuit and interest and plays a unique role in students' perceived support because it is the most proximal to classroom functioning. Furthermore, the sixth-grade students' pursuit of social goals and student interest explains the positive correlation between the students' social support and academic performance (Wentzel, 1998). To summarize, teachers can change students' intrinsic motivation through their social influence to achieve the result of influencing students' academic performance. Wentzel reviews the literature and indicates that teachers communicate socially valued goals and expectations to their students. Moreover, they provide contexts conducive to learning and the adoption of these goals, which are ultimately related to academic achievement (Wentzel, 1999).

\subsection{Peer factor}

In a school-based environment, students will be influenced by both teachers and their peers in daily life. Wentzel determines that perceived support from peers has significant implications for students' motivation to display prosocial forms of behavior and play a unique role in motivating them to help and cooperate with each other. Furthermore, students' motivation explained the relationship between perceived support and academic performance (Wentzel, 1998); moreover, the influence of peers on students may be either positive or negative. Wentzel determines that the peer has the potential to generate both a positive and a negative strong influence on students' motivational orientations toward school, which then affects their academic performance; however, the peer influence can be superseded (Wentzel, 1999). Because the peer group would frequently change, the influence by a specific peer group is, perhaps, transient; hence, the relationship with family, which is stable and predictable, is very important to contribute positive efforts. Furthermore, students' own social behavior will affect their peers' responses to their behavior, and students' choice of friends will determine their peers' influence. Wentzel determines that friendships, group acceptance and group membership play distinct roles in promoting academic performance; however, the relationship between peer relationships and academic 
performance cannot be fully explained without considering the mediational role of students' prosocial behavior (Wentzel and Caldwell, 1997). Parker determines that low-accepted children's friendships are lower than those of other children on most dimensions of quality. Having a friend, friendship quality and group acceptance leads to separate contributions for predicting loneliness (Parker and Asher, 1993). To summarize, students' friendship determines their peers' influence on them, which indirectly affects their academic performance. Ryan believes that peer group context can support or undermine adolescent motivation and academic performance. Students tend to select friends who are similar to themselves with respect to academic characteristics; however, after controlling for friend selection, the peer group context is still related to the students' academic performance (Ryan, 2001), which indicates that no matter how the students select their friends, the peer influences always exist.

\subsection{Individual factor}

All of the above are environmental factors, which often affect individual academic performance via internal changes. Individual characteristics vary from person to person, and the degree of impact is not the same. Wentzel determines that unique self-regulatory processes, including goal setting, interpersonal trust and problem-solving styles, are a key aspect of social competence that influences academic performance (Wentzel, 1991). Furthermore, the identity of students is generally either children or adolescents; as they grow older, their internal characteristics will change, leading to changes in the impact of environmental factors on them. Wentzel believes that with the increasing autonomous state that develops as children grow older, children's behavior can have a significant impact on parent, teacher and peer behavior (Wentzel, 1999). Therefore, some researchers have proposed the self-determination theory after studying the individual's psychological needs, which explains the individual's behavior in responding to the external environment. Ryan introduces the self-determination theory, which argues that the human being has three innate psychological needs: competence, autonomy and relatedness. When satisfied, these needs yield enhanced self-motivation, whereas, when thwarted, they can lead to diminished motivation (Ryan and Deci, 2000). Therefore, we construct a conceptual framework that integrates self-determination theory with school engagement and sort the literature after the emergence of school engagement by adapting the framework.

Overall, based on our review of the research, we conclude that there is a wide range of social relationships from family to school that have certain impacts on students' academic performance. As the first social relationship that students confront, many researchers believe that family factor has a positive impact on students' performance. When students grow up and leave home to school, the time that they stay with family gradually reduces, on the contrary, the time that they spend with teachers and peers increases. Furthermore, the teacher factor consists of direct and indirect impacts, while the peer factor has different effects according to students' network of friends and their individual factor. In addition, the impacts of family factor, teacher factor and peer factor vary with the individual factor of students. Many studies have shown that students' motivation and school engagement have positive impacts on their academic performance.

\section{The emergence of school engagement}

Using CiteSpace's cited literature visualization, we determine that two studies of Fredricks and Furrer about school engagement have been cited by many researchers. Fredricks believes that engagement is presumed to be malleable, responsive to contextual features and amenable to environmental change. Researchers describe the behavioral, emotional and 
IJCS

5,1

24

cognitive engagement and recommend studying engagement as a multifaceted construct. Engagement is associated with positive academic outcomes; however, the distinctions between the three types of engagement and between the concepts within each type need to be specified (Fredricks et al., 2004). Furrer determines that relatedness to parents, teachers and peers each uniquely contributed to students' engagement, particularly emotional engagement. This discussion examines the theoretical, empirical and practical implications of relatedness as a key predictor of children's academic motivation and performance (Furrer and Skinner, 2003). These two studies, as the two most cited studies, have considerable influence on follow-up studies.

\subsection{Follow-up studies of school engagement}

Many researchers have studied the follow-up study of school engagement from multiple perspectives. They determine that school engagement is an important variable that is related to social relationships and academic performance. Some researchers have analyzed the influence of social relationships on school engagement. Buhs determines that distinct forms of peer maltreatment and classroom engagement mediate the link between early peer rejection and changes in children's achievement. Children's reduced classroom participation to a greater extent compared to increases in school avoidance, anteceded decrements in children's achievement (Buhs et al., 2006). Kindermann determines that the magnitude of effects of peer groups on changes in academic engagement is relatively less; however, the evidence for group influences persists when controlling for peer selection and the influence of teacher and parent involvement (Kindermann, 2007). Roorda determines associations between affective qualities of teacher-student relationships and students' school engagement and performance. Moreover, stronger effects are determined with higher grades; nevertheless, the effects of negative relationships are stronger in primary compared to secondary schools (Roorda et al., 2011). Appleton determines that research supports the cyclical relations between engagement and academic performance (Appleton et al., 2008). Furthermore, some researchers reveal the components that affect a school's engagement. Wentzel determines that students' social competence with peers might be related to academic motivation and performance. Furthermore, school-level social systems can influence the nature and quality of peer interactions and relationships, as well as moderate their impact on academic performance (Wentzel, 2009). Therefore, by applying the self-determination theory discussed in Section 3.4, we can summarize the three components that affect school engagement, namely, autonomy, competence and relatedness, as shown in Figure 5.

\subsection{Autonomy}

According to self-determination theory, individuals should express their true preferences and act in accordance with their true selves. The degree of autonomy experienced by

Figure 5.

The selfdetermination theory and school engagement

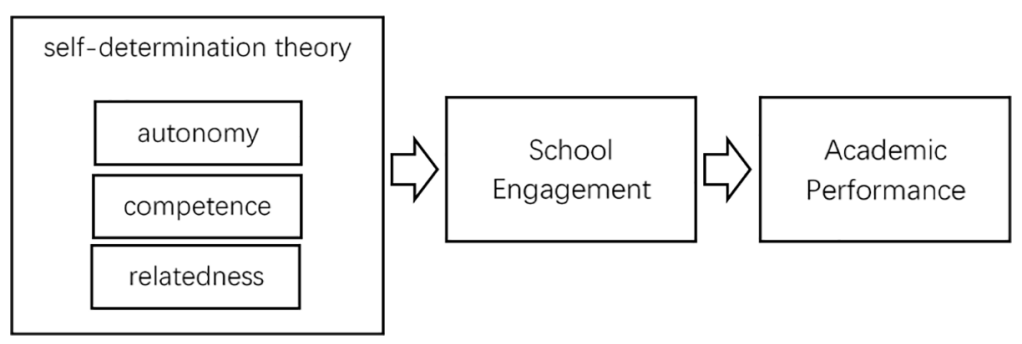


individuals in a particular field is related to their quality of engagement in that field. Hardre and Reeve demonstrate that students with greater autonomy in the school environment perform better academically (Hardre and Reeve, 2003).

Selection is a defining feature of all-natural groups, and peer selection is an important process by which students influence their peers. Peer selection possibly plays a key role in explaining how students' peers influence their academic performance. McPherson, Smith-Lovin and Cook determine that teenagers look for friends with similar academic performance and who will then strengthen their own academic achievement with time (McPherson et al., 2001). From this study, we determine that peers are apparently similar in various behaviors and attitudes, which can be explained by peer selection and peer influence process. Flashman examines the role of friendship selection on the academic performance of eight senior high school students and determines that high-achieving students are more likely to extend ties with other high-achieving students, while low-achieving students prefer the fellowship of other low-achieving students (Flashman, 2012).

Ryan and Deci determine that students' learning motivation is another powerful predictor of their academic performance (Ryan and Deci, 2000). Moreover, Wentzel determines that students' learning motivation has been proved to be socially constructed; social relationships, such as with peers, affect students' learning motivation (Wentzel, 2005). Ford believes that a person will pursue a goal as long as their emotions and personal beliefs are related to that goal and help maintain such a pursuit over time (Ford, 1992). Once students are willing to motivate themselves in academic engagement, they will place all their efforts into improving their academic performance.

\subsection{Competence}

In the academic field, competence may be the most frequently studied aspect of selfperception (Wigfield et al., 2007). Individuals should experience effectiveness in their interaction with the environment, thus forming their own judgment regarding their competence in a certain study; this judgment is often influenced by peers (Aronson and Steele, 2005). Researchers believe that the mastery level is related to the quality of engagement in a field. Note that academic competence is a powerful indicator of students' efforts and perseverance in school and of their emotional response to academic success and failure.

Dweck determines that children with confidence and security in their ability to succeed are likely to work hard. Despite the challenging nature of tasks, they will work harder to accomplish them (Dweck, 1986). Eccles, Wigfield and Schiefele argue that people's beliefs in their abilities seem to influence what they select to do and why they prefer certain activities over others. The stronger one's belief in personal competence and ability, the more likely one is to engage in certain academic activities (Eccles et al., 1998). However, Repetti, McGrath and Ishikawa determine that children with uncertain abilities tend to give up or not make a considerable effort in school (Repetti et al., 1999). Compare with praising students to boost their self-esteem, Yeager and Dweck determine that emphasizing students' potential to change and to overcome the challenges with effort, learning and help from others is more important (Yeager and Dweck, 2012).

Friendship, which is characterized by positive characteristics, such as self-expression, prosocial behavior and support, is related to higher school engagement. Students with positive peer relationships in schools are more likely to engage positively in school (GarciaReid, 2007). We tend to think that when students feel that their academic performance is accepted by peers, they have both the confidence and the ability to discuss ideas and criticize each other's work. Wentzel determines that peer acceptance behaviors positively 
IJCS
5,1

affect academic performance, while peer rejection behaviors are detrimental to it (Wentzel, 1994). Similarly, Kurdek and Sinclair observe that peer acceptance meets teenagers' requirement for interpersonal relationships and helps them develop a sense of satisfaction in school (Kurdek and Sinclair, 2000). Therefore, we expect peer acceptance to be positively correlated with academic engagement, thereby leading to improved academic performance. Besides, Lavy and Sand observe that the type of friends and their socio-economic background will determine whether the number of friends has a positive or negative impact on students' academic outcomes (Lavy and Sand, 2019). Fletcher reports that for girls, an increase in the number of friendships with students whose mothers are college-educated will improve their average scores, but not for boys (Fletcher et al., 2020). These show that different social backgrounds of friends will have different influences, and this is also related to the characteristics of students themselves.

Furthermore, some researchers introduce the big-fish-little-pond effect model, which states that students compare their academic ability to that of their classmates and use it as the basis for forming their own academic self-concept. When equally competent students compare themselves to more competent ones, their academic self-concept decreases; moreover, when they compare themselves to less competent students, their academic selfconcept is higher. Certain students who enter a low-ability school tend to have higher skills than the average level of other students, and the process of social comparison will lead to a higher academic self-concept (Marsh et al., 2001).

\subsection{Relatedness}

Relatedness, as a component of self-concept, is an important academic research field. Individuals are born with an inherent desire to connect with others; they both form crowds and establish social networks. Brown shows that, in high school, academic reputation can indicate students' membership in a particular group (Brown, 1989). Moreover, Connell and Wellborn state that if students meet their social relatedness requirements in school, they feel strongly attached to others and experience a positive sense of belonging and will actively engage in social and academic interactions (Connell and Wellborn, 1991).

The perspective of incentives states that the degree to which they believe they belong to a particular crowd is related to the quality of their engagement in the crowd's activities. Wentzel reports that students' perception of positive relationships with their peers may promote their social relatedness; however, this positive sense of relatedness may support active engagement in classroom activities. Nevertheless, perceiving negative relatedness is possible to cause alienation from classroom activities (Wentzel, 1999).

Many studies have demonstrated a relationship between school relatedness and academic engagement. Recently, studies that have directly investigated students' sense of relatedness with their peers show consistently positive impacts (Goodenow, 1993; Lynch and Cicchetti, 1997; Ryan et al., 1994; Skinner and Edge, 2002).

However, Voelkl reports that school relatedness is significantly correlated with achievement test scores in the fourth and seventh grades for white students but not for African-American students (Voelkl, 1997).

\section{Conclusion}

We use CiteSpace to analyze literature on the relationship between social relationships and academic performance. By analyzing the co-cited articles and highly cited articles, school engagement plays an intermediary role between social relationships and academic performance. Using the extended literature analysis of the important node literature, we determine that autonomy, competence and relatedness from the self- 
determination theory are three important factors that affect school engagement. This study introduces the impact of social relationships on academic performance and its possible mechanism, as well as contributes to the literature on the improvement of cognitive ability in crowd evolution. Furthermore, it brings social relationships to the research framework of crowd science.

Recently, with the increase of internet users, the analysis of the specific social networks and its impact on academic performance has become possible. Facebook has a real network structure of friends; however, at present, researchers only study the impact of using Facebook and other social media on academic performance; they do not analyze the impact of changes in a network structure of friends on academic performance. Kirschner reports that Facebook users have lower grade point average (GPA) and spend fewer hours per week studying compared to nonusers (Kirschner and Karpinski, 2010). Junco determines that time spent on Facebook is strongly and significantly negatively related to the overall GPA but only weakly related to time spent preparing for class. Furthermore, using Facebook for collecting and sharing information is positively predictive of the outcome variables; however, its usage for socializing is negatively predictive (Junco, 2012).

There are some researchers who study the influence of specific social network structure on academic performance, but they usually use subjective data such as questionnaire data, which lacks the objectivity of a real social network. Steglich reports that the difficulty of separating the effects of partner selection from the effects of social influence is a recurrent problem for analyzing a social network (Steglich et al., 2010). Lomi reports that students tend to assimilate the average performance of their friends and advisors. Furthermore, students attaining similar levels of academic performance possibly develop ties of friendship and advice (Lomi et al., 2011). Flashman reports that friends play an important role in the educational process; they provide support and resources and can both encourage and discourage academic achievement. Consequently, friends adolescents make may help to maintain and exacerbate inequality if friends are sorted on the basis of academic achievement. High-achieving students possibly extend ties to other high-achieving students, while low-achieving students are more likely to extend ties to other low-achieving students. Adolescents respond to changes in academic achievement by changing their friendship ties (Flashman, 2012).

There are limitations to the extant research. Students' psychological needs and school engagement are not operationalized and measured consistently across studies. More research is needed to understand the mediating role that relates to students' social relationships and academic performance. In the future, the relationship between social relationships and academic performance can be studied by analyzing the objective network structure of real social networks. The advantage of modern data process methods provides us with a more micro and detailed perspective to design and implement empirical research. Using mathematic models or simulation methods will greatly develop the depth and breadth of this research field. Hence, the trend of using information technology, such as data mining or data analysis, in this academic field will become the focus of many researchers.

\section{References}

Appleton, J.J., Christenson, S.L. and Furlong, M.J. (2008), "Student engagement with school: critical conceptual and methodological issues of the construct", Psychology in the Schools, Vol. 45 No. 5, pp. 369-386.

Aronson, J. and Steele, C.M. (2005), "Stereotypes and the fragility of academic competence, motivation, and self-concept", in Elliot, A.J. and Dweck, C.S. (Eds), Handbook of Competence and Motivation, Guilford Publications, New York, NY, pp. 436-456. 
Brown, B.B. (1989), "The role of peer groups in adolescents' adjustment to secondary school”, in Berndt, T.J. and Ladd, G.W. (Eds), Peer Relationships in Child Development, John Wiley and Sons, Oxford, pp. 188-215.

Buhs, E.S., Ladd, G.W. and Herald, S.L. (2006), "Peer exclusion and victimization: processes that mediate the relation between peer group rejection and children's classroom engagement and achievement?", Journal of Educational Psychology, Vol. 98 No. 1, pp. 1-13.

Connell, J.P. and Wellborn, J.G. (1991), "Competence, autonomy, and relatedness: a motivational analysis of self-system processes", in Gunnar, M.R. and Sroufe, L.A. (Eds), The MN Symposia on Child Psychology, Vol. 23 Self Processes and Development, Lawrence Erlbaum Associates, Hillsdale, NJ, pp. 43-77.

Dweck, C.S. (1986), "Motivational processes affecting learning”, American Psychologist, Vol. 41 No. 10, pp. 1040-1048.

Eccles, J.S., Wigfield, A. and Schiefele, U. (1998), "Motivation to succeed", in Damon, W. and Eisenberg, N. (Eds), Handbook of Child Psychology, John Wiley and Sons Inc., Hoboken, NJ, pp. 1017-1095.

Fan, X. and Chen, M. (2001), "Parental involvement and students' academic achievement: a Metaanalysis", Educational Psychology Review, Vol. 13 No. 1, pp. 1-22.

Flashman, J. (2012), "Academic achievement and its impact on friend dynamics", Sociology of Education, Vol. 85 No. 1, pp. 61-80.

Fletcher, J.M., Ross, S.L. and Zhang, Y. (2020), "The consequences of friendships: evidence on the effect of social relationships in school on academic achievement", Journal of Urban Economics, Vol. 116.

Ford, M.E. (1992), Motivating Humans: Goals, Emotions, and Personal Agency Beliefs, SAGE Publications, Thousand Oaks, CA.

Fredricks, J.A., Blumenfeld, P.C. and Paris, A.H. (2004), "School engagement: potential of the concept, state of the evidence", Review of Educational Research, Vol. 74 No. 1, pp. 59-109.

Furman, W. and Buhrmester, D. (1992), "Age and sex differences in perceptions of networks of personal relationships", Child Development, Vol. 63 No. 1, pp. 103-115.

Furrer, C. and Skinner, E. (2003), "Sense of relatedness as a factor in children's academic engagement and performance", Journal of Educational Psychology, Vol. 95 No. 1, pp. 148-162.

Garcia-Reid, P. (2007), "Examining social capital as a mechanism for improving school engagement among low income Hispanic girls", Youth and Society, Vol. 39 No. 2, pp. 164-181.

Goodenow, C. (1993), "Classroom belonging among early adolescent students: relationships to motivation and achievement", The Journal of Early Adolescence, Vol. 13 No. 1, pp. 21-43.

Hardre, P.L. and Reeve, J. (2003), "A motivational model of rural students' intentions to persist in, versus drop out of, high school”, Journal of Educational Psychology, Vol. 95 No. 2, pp. 347-356.

Junco, R. (2012), "The relationship between frequency of Facebook use, participation in Facebook activities, and student engagement", Computers and Education, Vol. 58 No. 1, pp. 162-171.

Kindermann, T.A. (2007), "Effects of naturally existing peer groups on changes in academic engagement in a cohort of sixth graders", Child Development, Vol. 78 No. 4, pp. 1186-1203.

Kirschner, P.A. and Karpinski, A.C. (2010), "Facebook ${ }^{\circledR}$ and academic performance", Computers in Human Behavior, Vol. 26 No. 6, pp. 1237-1245.

Kurdek, L.A. and Sinclair, R.J. (2000), "Psychological, family, and peer predictors of academic outcomes in first - through fifth-grade children", Journal of Educational Psychology, Vol. 92 No. 3, pp. 449-457.

Lavy, V. and Sand, E. (2019), "The effect of social networks on students' academic and non-cognitive behavioural outcomes: evidence from conditional random assignment of friends in school", The Economic Journal, Vol. 129 No. 617, pp. 439-480. 
Lomi, A., Snijders, T.A.B., Steglich, C.E.G. and Torlo, V.J. (2011), "Why are some more peer than others? Evidence from a longitudinal study of social networks and individual academic performance", Social Science Research, Vol. 40 No. 6, pp. 1506-1520.

Lynch, M. and Cicchetti, D. (1997), “Children's relationships with adults and peers: an examination of elementary and junior high school students", Journal of School Psychology, Vol. 35 No. 1, pp. 81-99.

McPherson, M., Smith-Lovin, L. and Cook, J.M. (2001), "Birds of a feather: homophily in social networks", Annual Review of Sociology, Vol. 27 No. 1, pp. 415-444.

Marsh, H.W., Köller, O. and Baumert, J. (2001), "Reunification of east and west German school systems: longitudinal multilevel modeling study of the big-fish-little-pond effect on academic selfconcept", American Educational Research Journal, Vol. 38 No. 2, pp. 321-350.

Parker, J.G. and Asher, S.R. (1993), "Friendship and friendship quality in Middle childhood: links with peer group acceptance and feelings of loneliness and social dissatisfaction", Developmental Psychology, Vol. 29 No. 4, pp. 611-621.

Repetti, R., McGrath, E.P. and Ishikawa, S.S. (1999), "Daily stress and coping in childhood and adolescence", in Goreczny, A.J. and Hersen, M. (Eds.), Handbook of Pediatric and Adolescent Health Psychology, Allyn and Bacon, Needham Heights, MA, pp. 343-360.

Resnick, M.D., Bearman, P.S. and Blum, R.W. (1997), "Protecting adolescents from harm: findings from the national longitudinal study on adolescent health", JAMA, Vol. 278 No. 10, pp. 823-832.

Roorda, D.L., Koomen, H.M.Y., Spilt, J.L. and Oort, F.J. (2011), "The influence of affective teacherstudent relationships on students' school engagement and achievement: a Meta-analytic approach", Review of Educational Research, Vol. 81 No. 4, pp. 493-529.

Ryan, A.M. (2001), "The peer group as a context for the development of young adolescent motivation and achievement", Child Development, Vol. 72 No. 4, pp. 1135-1150.

Ryan, R.M. and Deci, E.L. (2000), "Self-determination theory and the facilitation of intrinsic motivation, social development, and well-being", American Psychologist, Vol. 55 No. 1, pp. 68-78.

Ryan, R.M., Stiller, J.D. and Lynch, J.H. (1994), "Representations of relationships to teachers, parents, and friends as predictors of academic motivation and self-esteem", The Journal of Early Adolescence, Vol. 14 No. 2, pp. 226-249.

Skinner, E. and Edge, K. (2002), "Parenting, motivation, and the development of children's coping", Nebraska Symposium on Motivation, Vol. 48, pp. 77-143.

Steglich, C., Snijders, T.A.B. and Pearson, M. (2010), "Dynamic networks and behavior: separating selection from influence", Sociological Methodology, Vol. 40 No. 1, pp. 329-393.

Voelkl, K.E. (1997), "Identification with school", American Journal of Education, Vol. 105 No. 3, pp. 294-318.

Wentzel, K.R. (1991), "Relations between social competence and academic achievement in early adolescence", Child Development, Vol. 62 No. 5, pp. 1066-1078.

Wentzel, K.R. (1994), "Relations of social goal pursuit to social acceptance, classroom behavior, and perceived social support”, Journal of Educational Psychology, Vol. 86 No. 2, pp. 173-182.

Wentzel, K.R. (1998), "Social relationships and motivation in Middle school: the role of parents, teachers, and peers", Journal of Educational Psychology, Vol. 90 No. 2, pp. 202-209.

Wentzel, K.R. (1999), "Social-motivational processes and interpersonal relationships: implications for understanding motivation at school", Journal of Educational Psychology, Vol. 91 No. 1, pp. 76-97.

Wentzel, K.R. (2005), "Peer relationships, motivation, and academic performance at school", in Elliot, A. J. and Dweck, C.S. (Eds), Handbook of Competence and Motivation, Guilford Publications, New York, NY, pp. 279-296.

Wentzel, K.R. (2009), "Peers and academic functioning at school", in Rubin, K.H., Bukowski, W.M. and Laursen, B. (Eds), Handbook of Peer Interactions, Relationships, and Groups, The Guilford Press, New York, NY, pp. 531-547. 
Wentzel, K.R. and Caldwell, K. (1997), "Friendships, peer acceptance, and group membership: relations to academic achievement in Middle school", Child Development, Vol. 68 No. 6, pp. 1198-1209.

Wigfield, A., Eccles, J.S., Schiefele, U., Roeser, R.W. and Davis-Kean, P. (2007), "Development of achievement motivation", in Damon, W., Lerner, R.M. and Eisenberg, N. (Eds), Handbook of Child Psychology, John Wiley and Sons, Inc.

Yeager, D.S. and Dweck, C.S. (2012), "Mindsets that promote resilience: when students believe that personal characteristics can be developed", Educational Psychologist, Vol. 47 No. 4, pp. 302-314.

\section{Corresponding author}

Leiju Qiu can be contacted at: leijuqiu@outlook.com

For instructions on how to order reprints of this article, please visit our website: www.emeraldgrouppublishing.com/licensing/reprints.htm

Or contact us for further details: permissions@emeraldinsight.com 